\title{
In search of an ideal drug for safer treatment of obesity: The false promise of pseudoephedrine
}

\author{
Antonio Munafó ${ }^{1} \cdot$ Stefano Frara $^{2} \cdot$ Norberto Perico $^{3} \cdot$ Rosaria Di Mauro $^{1} \cdot$ Monica Cortinovis $^{3} \cdot$ Chiara Burgaletto $^{1}$. \\ Giuseppina Cantarella ${ }^{1} \cdot$ Giuseppe Remuzzi $^{3} \cdot$ Andrea Giustina $^{2} \cdot$ Renato Bernardini $^{1}$
}

Accepted: 27 April 2021 / Published online: 4 May 2021

(c) The Author(s) 2021

\begin{abstract}
Obesity is a major public health problem worldwide. Only relatively few treatment options are, at present, available for the management of obese patients. Furthermore, treatment of obesity is affected by the widespread misuse of drugs and food supplements. Ephedra sinica is an old medicinal herb, commonly used in the treatment of respiratory tract diseases. Ephedra species contain several alkaloids, including pseudoephedrine, notably endowed with indirect sympathomimetic pharmacodynamic properties. The anorexigenic effect of pseudoephedrine is attributable primarily to the inhibition of neurons located in the hypothalamic paraventricular nucleus (PVN), mediating satiety stimuli. Pseudoephedrine influences lipolysis and thermogenesis through interaction with $\beta 3$ adrenergic receptors and reduces fat accumulation through down-regulation of transcription factors related to lipogenesis. However, its use is associated with adverse events that involve to a large extent the cardiovascular and the central nervous system. Adverse events of pseudoephedrine also affect the eye, the intestine, and the skin, and, of relevance, sudden cardiovascular death related to dietary supplements containing Ephedra alkaloids has also been reported. In light of the limited availability of clinical data on pseudoephedrine in obesity, along with its significantly unbalanced risk/benefit profile, as well as of the psychophysical susceptibility of obese patients, it appears reasonable to preclude the prescription of pseudoephedrine in obese patients of any order and degree.
\end{abstract}

Keywords Dietary restriction $\cdot$ Obesity $\cdot$ Sympaticomimetic drugs $\cdot$ Severe adverse events

\section{Introduction}

Obesity is a chronic and multifactorial [1] disease characterized by increased body weight due to an excessive fat accumulation as a result of daily intake excess and inadequate calorie expenditure [2]. Such imbalance determines, in the

Antonio Munafò and Stefano Frara these authors contributed equally to this work

Andrea Giustina and Renato Bernardini these authors share senior authorship

Renato Bernardini

bernardi@unict.it

1 Department of Biomedical and Biotechnological Sciences, University of Catania School of Medicine, Catania, Italy

2 Institute of Endocrine and Metabolic Sciences (IEMS), San Raffaele Vita-Salute University, Milano, Milano, Italy

3 Istituto Di Ricerche Farmacologiche "Mario Negri”, Bergamo, Italy long run, an excess in adipose tissue that leads, firstly, to an overweight body phenotype and, at a later stage, to the development of a body weight disorder called obesity [3].

In previous years, different approaches to obesity have led to the development of new techniques to overcome the biases related to the obesity definition. Evaluation of the body composition by Dual Energy X-Ray Absorptiometry (DEXA) or electrical bio-impedance analysis (BIA) provided reliable data in many trials [4], but higher costs, radiation exposure, patient inconvenience and less availability represent limitations to the widespread of these technologies.

Obesity represents a worldwide health problem in adults, as well as among children and adolescents, and significantly increases the risk of developing metabolic syndrome, type 2 diabetes mellitus, hypertension and cardiovascular and kidney diseases leading to high all-cause mortality [5, 6]. In addition, numerous cohort studies have shown the link between obesity and the increased incidence of different types of cancer, including colon, postmenopausal breast, endometrial cancers and esophageal adenocarcinoma [7, 8]. 
Personalized dietary regimens [9] and physical activity are the cornerstones of anti-obesity therapy, which should be performed under medical supervision; however, this strategy is not easy to achieve as many patients show poor adherence and a low success rate [10]. Pharmacological therapy of obesity is considered a controversial issue because in many cases medicines have modest efficacy while exhibiting considerable adverse events [11]. The major pathways implicated in controlling metabolism and nutrient intake include the hypothalamic system leptinmelanocortin [12, 13], the adrenergic [14], cannabinoid [15], dopaminergic [16], and opioidergic [17] systems in the hypothalamus and other brain regions. These selected central nervous system (CNS) pathways are promising targets for the development of the most recent weight-loss therapies. Moreover, while starting an anti-obesity medical treatment, the clinicians should pay particular attention to possible concomitant obesogenic prescription medications, including all drugs in the classes of glucocorticoids, $\beta$-blockers, antihistamines, as well as selected agents in the classes of antidepressants, antipsychotics, antidiabetics, and contraceptives that are progestin-only [18]. Based on the analysis of national United States (US) databases, it has been observed that a quarter of the American population is assuming at least one of these drugs which are significantly associated with worse weight-loss outcomes [19]. For this reason, relevant scientific data are stressing the message that clinicians, tackling obesity, should try to minimize the use of obesogenic drugs and focus on prescribing agents that are weight neutral or that trigger weight loss, when those options are available and appropriate [19].

Another innovative approach aimed to maximize weight loss is represented by the use of targeted poly-pharmacology or unimolecular poly-agonists displaying activity upon multiple receptors. These include Melanocortin-4 receptor (MC4R) agonist/Glucagon-like peptide-1 receptor (GLP-1R) agonist combination [20-22].

In severe cases of obesity, bariatric surgery may be a viable option that can produce profound weight loss and may lead to diabetes and dyslipidemia remission, regardless of the procedure type [23]. However, it should be disclosed that surgery is also associated with an increased risk of developing obesity-related comorbidities and possible weight recovery in subsequent years [24, 25].

Although the fields of obesity research and related drug discovery have seen many exciting developments, only a few investigational agents are likely to meet the required criteria and to advance into the marketplace [26]. The related shortage of useful and authorized treatments leaves an open field to the improper use of drugs or dietary supplements whose safety and efficacy have not been confirmed. The use of various weight-loss supplements, such as dietary supplements and herbal products, is gaining worldwide acceptance, but qualitative and quantitative monitoring of pharmaceutical agents present in weightloss supplements are needed [27].

In the present review we i) discuss the criteria required for a valuable anti-obesity drug; ii) summarize the risk and rewards of the most common anti-obesity medicines, and; iii) assess the potentiality and risks of pseudoephedrine in obese patients.

\section{The ideal anti-obesity drug}

Given the multifactorial pathogenesis of obesity [1], its treatment involves an integrated approach between different intervention modalities. The first and fundamental therapeutic approach to curb the pandemic problem of obesity must be a change in the lifestyle through an adequate diet and the practice of a regular physical activity program adapted to individual abilities and state of health [28]. The pharmacological treatment should take place only after a poor effectiveness of diet and exercise in either inducing or maintaining weight-loss has been demonstrated. Currently not many pharmacological options are available and some of the drugs offer limited advantages over lifestyle intervention, and also the cost and side effects require that their use should be restricted to particular cases [29]. The properties of an ideal antiobesity drug would be to produce a sustained decrease in body fat and/or visceral fat in a dose-dependent manner [30]. More specifically, the drug would have to decrease appetite, be active in the long-term, and preferably not producing tolerance or rebound effects. The definition of the benefit of an ideal anti-obesity treatment should not be restricted to the evaluation of the amount of body weight lost during the treatment but rather extended to the improvement of several comorbid conditions related to obesity [31, 32]. Furthermore, it should be inexpensive and easy to use because obesity is a condition that overtly affects individuals belonging to a low socioeconomic status, whereby affordability and availability become two decisive factors [33]. In addition, the ideal drug should have a simple regimen of administration (oral or weekly) in order to facilitate patient adherence [32]. Another ideal characteristic should be that the drug acts pleiotropically, improving other clinical aspects such as control of blood pressure or lipids, quite often associated with obesity [34].

However, the utmost complexity of the neurobiology of this disorder, with its redundant pathways, reduces the ability to discover a single-acting drug, suggesting that multiple approaches with different mechanisms are needed to produce a substantial and persistent weight-loss. 


\section{Anti-obesity medications (AOMs): a large panel of treatment options}

Despite the wide variety of molecules available, to date obesity does not yet have a definitive drug therapy. All anorectic drugs act through the most varied mechanisms of action, favoring a reduction in food intake and in the absorption of nutrients [35]. These include GLP-1R agonists [36-38], Type 2 sodium-glucose cotransporter (SGLT2) inhibitors (which, although associated with weight loss in people with type 2 diabetes due to their mechanism of action, are not generally considered antiobesity drugs) [39-41], sympathomimetics [42, 43], serotoninergic system drugs [44-46], opioid $\mu$ receptor antagonists/weak inhibitor of neuronal dopamine and norepinephrine reuptake inhibitors [47, 48], and pancreatic lipase inhibitors $[49,50]$ (Fig. 1). In particular, all these medications are currently approved by both the Food and Drug Administration (FDA) and the European Medicines Agency (EMA), with the exception of sympathomimetics and serotoninergic drugs, which have been approved, so far, only by FDA. In front of such a wide range of options, as well as of the unmet need for every obese patient, the task to accomplish remains finding out the optimal individually tailored therapeutic regimen to treat obesity.
Fig. 1 Effect of available antiobesity drugs: Mean weight loss expressed in $\mathrm{Kg}(\mathbf{A})$ and mean weight change expressed in $\%$ (B) at the last-observation-carried-forward (LOCF), reported in yearly trials with different drugs at the highest dose (N.A. not-available data)

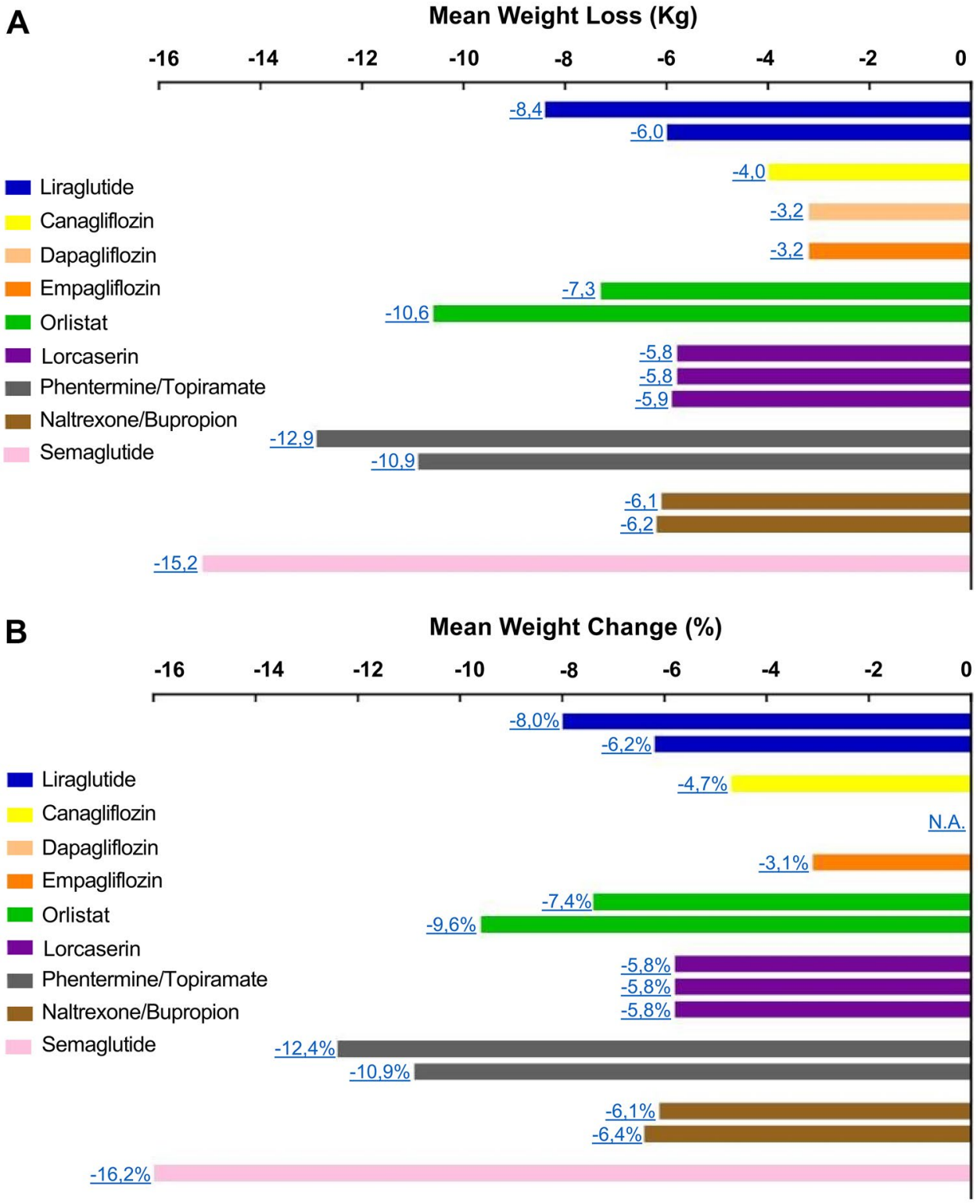




\section{Ephedra compounds}

One of the oldest medicinal herbs is probably Ephedra, also known as "Ma-huang", which presents a long history in traditional Chinese medicine as a treatment for bronchial asthma, colds, headache, and nasal congestion [51]. In particular, Ephedra sinica, a member of the Ephedraceae family, is the most commonly used in preparations and extracts. Ephedra includes several sympathomimetic substances, such as ephedrine, pseudoephedrine, nor-ephedrine, methylephedrine, and methyl-pseudoephedrine, all substances with molecular structures related to catecholamines and amphetamines [52]. The alkaloid content of Ephedra species is highly variable, depending upon the type, the parts of the plant used and the method of extraction, the most represented being ephedrine and its stereoisomer pseudoephedrine (Fig. 2). The latter substance is characterized by an ephedrine-like effect but less pronounced cardiac action, less adverse effects and higher diuretic activity [53, 54]. Despite its long history, the use of Ephedra herb has declined throughout the years, due to the lack of concrete effectiveness and the poor labeling for possible toxicity. However, recently, many companies started marketing dietary supplements for weight reduction, containing Ephedra extract. The wide availability of these non-prescription products and the wrong concept of safety have increased the misuse and abuse of the herb and relative mounting evidence of possible hazards.

\subsection{Pharmacodynamics and pharmacokinetics}

From a pharmacodynamics perspective, pseudoephedrine presents a sympathomimetic action both directly, by exerting agonist activity on $\beta_{1}, \beta_{2}$ and $\alpha_{1}$ adrenergic receptors, and indirectly, by inducing the release of norepinephrine from sympathetic neuron terminals, enhancing the effects of catecholamines [55]. Ephedrine and pseudoephedrine additional action of depleting the endogenous catecholaminergic reserves may explain the onset of tachyphylaxis after repeated dosing [56]. By virtue of their molecular structure, ephedrine and pseudoephedrine stimulate $\alpha$ adrenergic receptors at cavernous vein plexuses, determining its nasal decongestant effect [57]. Such apparently basic pharmacological mechanism accounts for either its therapeutic, as well as for the most evident adverse effects [58]. Pseudoephedrine increases hearth rate and contractility, induces constriction of bronchial and peripheral vessels smooth muscle, and affects the function of CNS [59] (Fig. 3). Because of these pharmacodynamic characteristics, patients under treatment or who recently discontinued therapy with monoaminoxidase inhibitors (MAOi), should not take pseudoephedrine for the increased risk of hypertensive episodes, such as paroxystic hypertension and malignant hyperthermia. Moreover, pseudoephedrine enhances the effects of other sympathomimetic drugs, thus increasing the risk of intense vasoconstriction and consequent possible hypertensive seizures; similarly, it is not recommended its use concomitantly with reversible inhibitors
Fig. 2 Structure of alkaloids from Ephedra sinica: Ephedra sinica was the first species of Ephedra used therapeutically in China. E. sinica has a strong pine odor and astringent taste, which accounts for its Chinese name (Ma-huang) which can be translated as 'yellow astringent'. The wide range of pharmacological activities showed by this plant are related to the content of ephedrine-type alkaloids. (-)- Ephedrine and (+)-Pseudoephedrine occurs as the main sympathomimetic alkaloids

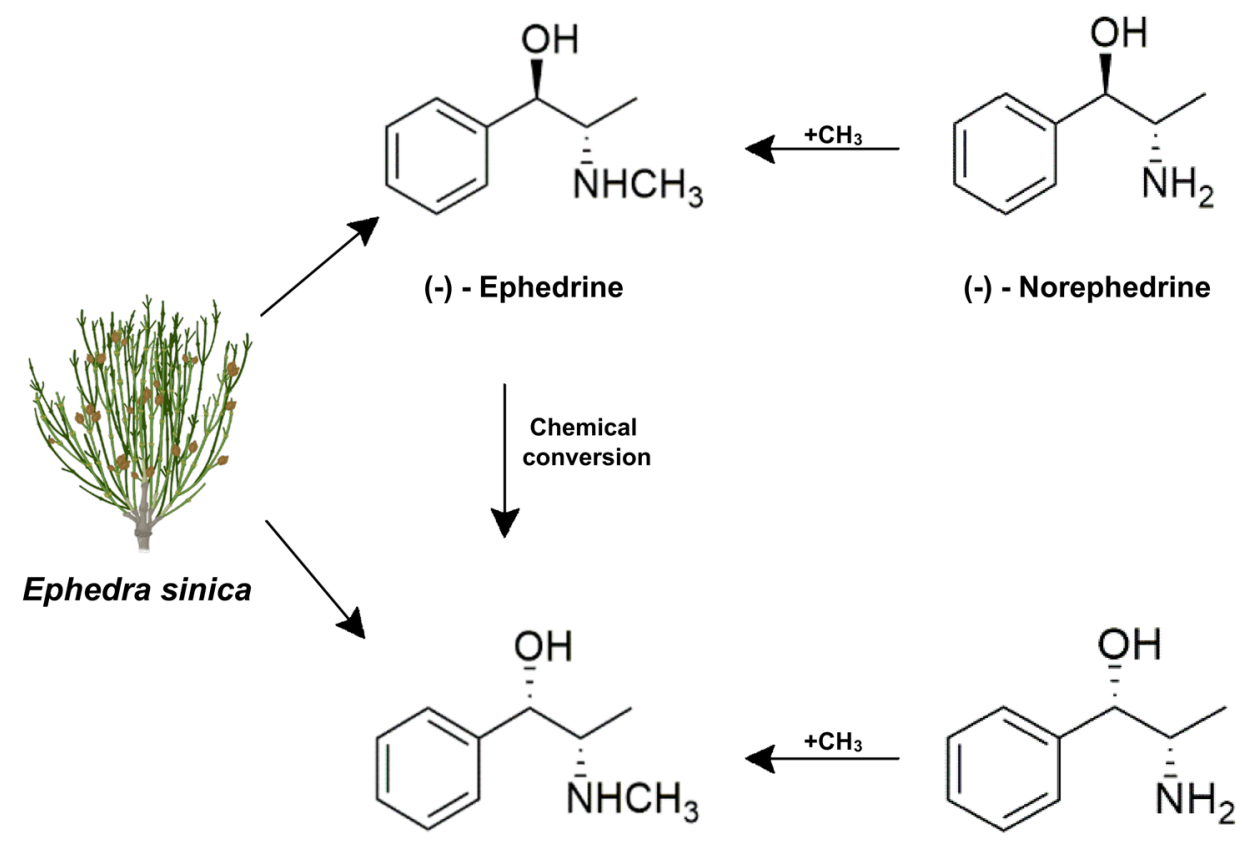

(+) - Pseudoephedrine

(+) - Norpseudoephedrine 
Fig. 3 Effects of Pseudoephedrine: Pseudoephedrine is a sympathomimetic agonist that also displays indirect sympathetic activation enhancing the release of norepinephrine from sympathetic neurons. This pharmacological mechanism seems to account for most of the pseudoephedrine's therapeutic efficacy, as well as its notable adverse effects. Characteristic effects of adrenergic receptor stimulation include enhanced cardiac rate and contractility, peripheral vasoconstriction, bronchodilation, and central nervous system (CNS) stimulation. The vasoconstrictor, mainly, and bronchodilator effects explain the traditional use of pseudoephedrine as a nasal decongestant and anti-asthmatic. CNS stimulation encompasses the inhibiting effect on satiety-related hypothalamic neurons that, combined with the thermogenic effect and the increased lipolytic activity, is purported to afford the renowned slimming effect

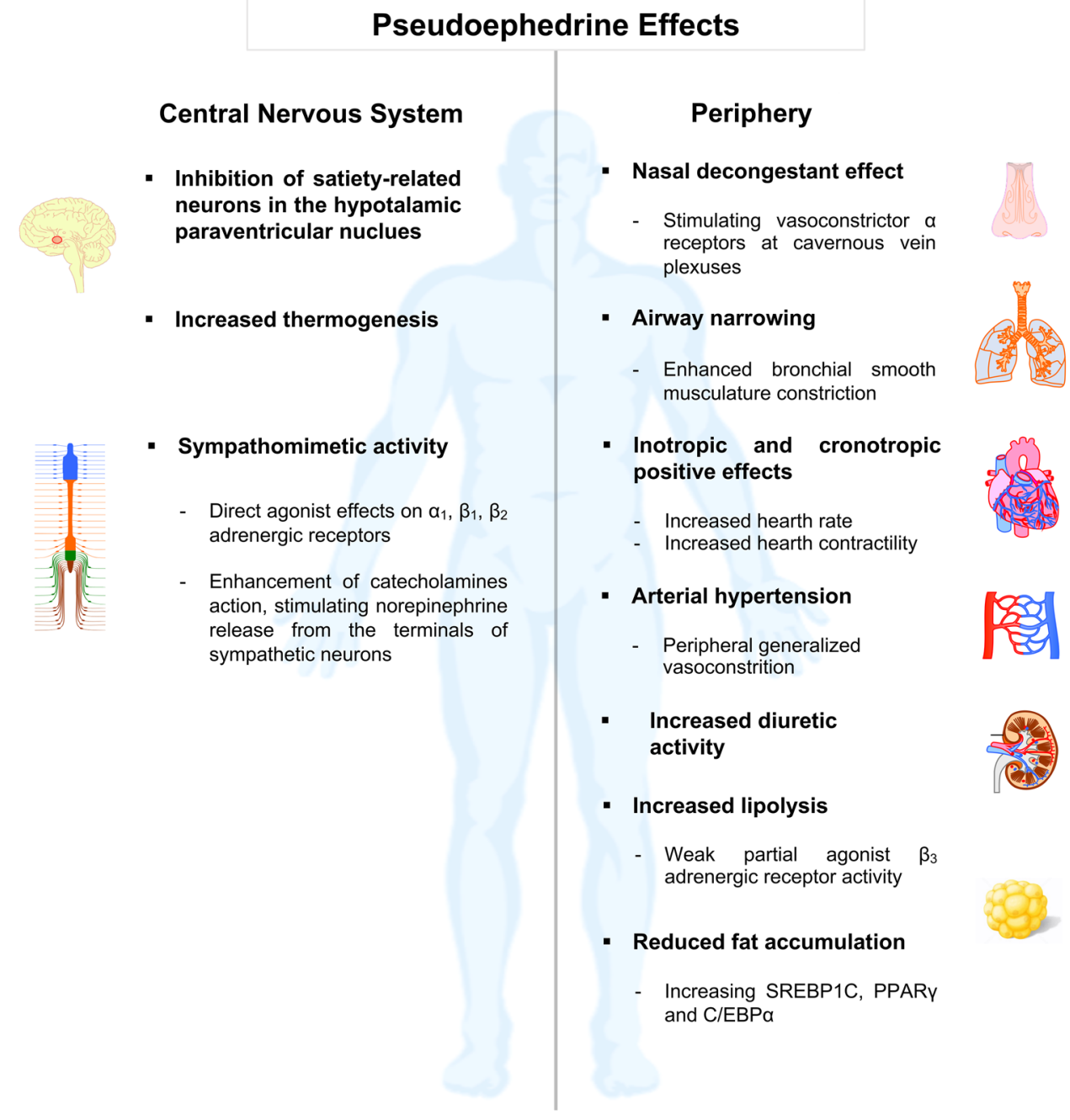

of monoaminoxidase A (RIMA) and ergot alkaloids, for the increased risk of vasoconstriction and/or hypertensive crises and severe arrhythmias $[60,61]$. As a sympathomimetic amine and precursor of amphetamine-like metabolites, pseudoephedrine owes its slimming properties to its anorectic action exerted through the inhibition of the activity of hypothalamic neurons of satiety, located in the hypothalamic paraventricular nucleus (PVN) and distinctively involved in the regulation of food intake, energy and sleep [62]. Furthermore, Vansal and Ferrel have proven that ephedrine isomers are able to interact with $\beta 3$ adrenergic receptors involved in lipolysis and thermogenesis [56]. Recent studies have shown that both ephedrine and pseudoephedrine are able to reduce fat accumulation by increasing the levels of downregulators of the lipogenic transcriptional factors, such as sterol regulatory element-binding protein 1C (SREBP1C), peroxisome proliferator-activated receptor gamma (PPAR $\gamma$ ), and CCAAT/enhancer-binding protein $\alpha(\mathrm{C} / \mathrm{EBP} \alpha)[63,64]$. The previously mentioned CNS stimulant activity, supported by its ability to cross the blood-brain barrier, combined with the thermogenic action, the anti-lipogenic activity, and the appetite suppressant effect [65], led several manufacturers to include pseudoephedrine and Ephedra compounds in the formulation of diet supplements to promote enhanced weight loss in obesity and improved performance in endurance training or body-building [66].

Pseudoephedrine does not undergo hepatic first-pass metabolism and its gastrointestinal absorption is rapid and complete. The peak of plasma concentration is 500-900 $\mu \mathrm{g} / \mathrm{l}$ and is reached about $2 \mathrm{~h}$ after oral administration of $180 \mathrm{mg}$ pseudoephedrine. The plasma half-life is about 5-8 h, but the plasma concentrations vary considerably between individuals $[67,68]$. Pseudoephedrine is resistant to the action of monoaminoxidase (MAO) and is excreted, mainly in an unmodified form, through the renal emunctories. Several pharmacokinetic studies have shown that at high urine $\mathrm{pH}$, pseudoephedrine, as a weak base, is non-ionized, thus it is easily reabsorbed from the renal tubules, whereas at low urine $\mathrm{pH}$, ephedrine is electrically charged and is cleared faster $[69,70]$. Only a $1 \%$ fraction of pseudoephedrine is 
eliminated via the liver, by $\mathrm{N}$-demethylation and formation of nor-pseudoephedrine (catine). Additionally, it has been demonstrated that there was no correlation between the halflife of pseudoephedrine and the severity or the amount of symptoms experienced by the subjects [71].

\subsection{Clinical data}

After the first studies in the 1970s, the use of Ephedrine products was widespread in the following decades in Europe and in North America. Such exceeding consumption was promoted by the classification of these substances as nutritional supplements for slimming [72]. Despite a comprehensive characterization of the mechanisms of action of pseudoephedrine, clinical data on the use of this compound in obesity are quite surprisingly limited. Only a single placebo-controlled weight-loss study of a slow-release formulation of pseudoephedrine (120 mg/day), conducted in 72 patients for 12 weeks, is available in the literature [73]. The two groups in the study had similar anthropometric characteristics (baseline BMI $29.2 \mathrm{~kg} / \mathrm{m}^{2}$ in the pseudoephedrine treatment group vs 28.5 in the placebo group). Weight loss at the end of the study overlapped in the two groups $(4.6 \mathrm{~kg}$ pseudoephedrine vs. $4.5 \mathrm{~kg}$ placebo), with no statistical significance at any intermediate point of the study. Also, there was no difference in appetite reported by patients in the two subgroups. Controlled clinical studies aimed at verifying the effects of higher doses of pseudoephedrine are not available. Furthermore, there are no evidence that pseudoephedrine would cause less dependence than ephedrine [73].

However, several studies have been conducted to investigate the association between the consumption of food supplements and drugs containing ephedra compounds and the onset of adverse events [74]. Between 1997 and 1999, the FDA received more than 140 reports of adverse events associated with the use of dietary supplements containing ephedra alkaloids. Among the 87 events that have been definitively, probably, or possibly related to the use of these food supplements, 10 resulted in death, 13 in permanent damage, while the remaining cases outcome to a full recovery. The most frequently observed events included hypertension, palpitations and, within neurological symptoms, seizures and stroke [75]. Using the comprehensive database Adverse Reaction Monitoring System of the FDA, Samunek and colleagues assessed the possible cardiovascular toxicity associated with the use of dietary supplements containing Ephedra. The authors have assessed a time correlation between ephedra consumption and 37 cases of stroke, half of which hemorrhagic, 10 cases of myocardial infarction and 11 cases of sudden death. They also concluded that, although pathogenesis is not fully defined yet, the cardiovascular toxic effects associated with ephedra were not limited to massive doses and may be associated with serious complications even in the apparent absence of underlying cardiovascular disease [76]. Analyzing a stroke registry since 1988, Cantu et al. found that 22 out of 2500 stroke patients manifested the event in a way associated with taking an overthe-counter (OTC) cough and cold sympathomimetic drug, containing phenylpropanolamine and pseudoephedrine. The relationship with the drug was established on the basis of a clear temporal association and after excluding other plausible known causes. Almost all events were found to be hemorrhagic and the tests carried out support the hypothesis that a hypertensive crisis and/or a similar vascular mechanism may lay at the basis of the event [77].

An extended meta-analysis, assessing the safety of Ephedra and ephedrine containing products for weight loss and athletic performance, reviewed the results of 50 controlled trials, all case reports for Ephedra compounds in the FDA MedWatch, as well as all case reports identified in published literature and a very large file of symptoms reported to a manufacturer of Ephedra-containing dietary supplements. The authors collected sufficient evidence to conclude that the use of ephedrine and Ephedra compounds resulted in two-to-three times increased risk of psychiatric symptoms, autonomic symptoms, upper gastrointestinal symptoms, tachycardia and hypertension compared to placebo. They also found a high number of case reports of serious adverse events occurring, in the absence of other possible causes, in young patients who used Ephedra or ephedrine, strengthening the possibility of a causal relationship [78]. Consequently, it has become difficult for manufacturing companies to oppose to the withdrawal of these combinations by the FDA, that, finally, in 2004 banned Ephedra and ephedrine products due to the unpredictable risk of adverse events. [79].

Despite the severity of the measures taken, the use of Ephedra alkaloids has not been stopped, supported also by the availability of these substances on the Internet and by the wrong, populist belief that, as they are of natural origin, these products are characterized by an excellent safety profile. As proof of this, numerous published reports underline such unpredictability of the effects of Ephedra alkaloids, and how numerous and variable may the related adverse events be [57]. In particular, the adverse events of pseudoephedrine are mainly concerning the cardiovascular system, supported by the increased availability of catecholamines and by the subsequent overstimulation of the adrenergic receptors. In addition to hypertension [80], regarded to as the most common adverse event, numerous cases of angina pectoris and myocardial infarctions have been reported also in young, healthy patients with no risk factors and after assumption of the recommended dose of an OTC cold remedy containing pseudoephedrine [81-84]. In many of the reported cases, the absence of a significant coronary disease and the other tests 
performed were consistent with an acute myocardial infarction caused by acute vasospasm caused by the adrenomimetic effects of the medication [85]. Of particular interest is the report by Fidan and colleagues, who described a case of ST-elevation myocardial infarction (STEMI) after the use of pseudoephedrine. This is the first study in literature in which the cardiac toxic effects of pseudoephedrine were confirmed by measuring the serum drug concentration. A causal relationship between drug intake and the cardiac event has then been established [86].

An identical pathophysiological mechanism was postulated to justify the onset of ischemic colitis following oral administration of pseudoephedrine-based decongestants [87]. This adverse event occurred in the absence of a major cardiovascular risk factor, hemodynamic instability, or hypercoagulability state, thus excluding major conditions predisposing the onset of this acute event. Given the clearcut temporal relationship between ingestion of the drug and the occurrence of symptoms, the OTC medication was, therefore, the most likely cause of this ischemic colitis [87]. In other case reports, ischemic colitis occurred with variable dosage and duration of treatment with pseudoephedrine, ranging from 60 to $900 \mathrm{mg}$ per day and for a period between 5 days and 2 years [88-91]. Together, these data underscore the need to collect a scrupulous drug history, including the ingestion of OTC and herbal supplements in ischemic colitis patients, with special regard to young patients.

The effects of pseudoephedrine are not exclusive to the cardiovascular system. The mixed-sympathomimetic properties of the ephedra compounds also influence the central nervous system, leading to increased presynaptic calcium-independent release of catecholamines, as well as to postsynaptic $\beta 1$ and $\beta 2$ activation [92]. This stimulating action on the CNS may become manifest during treatment through the onset of restlessness, insomnia and anxiety with consequent reduced concentration capacity and alteration of the mood state [93]. Therefore, such increase in noradrenergic tone, combined with dopamine release, can also lead to the onset of psychotic symptoms [94, 95]. This is not surprising when considering the chemical structure of these compounds, which can be classified as natural amphetamines [96]. The similarity with these substances does not end in the analogy of the chemical asset, but can be extended to the clinical phenomenology of induced psychoses, characterized mainly by a paranoid phenotype with delusions of persecution, and auditory and visual hallucinations [97] (Table 1). The first cases reported in the literature date back to the early 1970 s and, since then, the number of case reports has steadily increased [92, 98-100]. Most ephedrine/pseudoephedrine-induced manic episodes involve a pre-existing mood disorder history, suggesting that ephedrine may exacerbate pre-existing mood disorders, or precipitate a previously unproven one [101-104]. Consistently with these data, several cases have been described in which the use of products containing pseudoephedrine has been correlated with the onset of manic and psychotic symptoms in a schizoaffective patient after a period of remission of 10 years [105]. Others have reported two mania episodes triggered by pseudoephedrine in the context of a bipolar manic disorder [106]. Nevertheless, there are also reports of ephedrine-induced mania in the absence of a previous history of depression or other mood disorders, suggesting that these drugs may potentially initiate sustained mood dysregulation [107]. Such association of behavioral side effects with the use/abuse of OTC cold medications containing ephedrine and pseudoephedrine, has also been shown in children [108, 109]. All three reported cases describe similar clinical pictures of severe acute psychosis, which required several days of hospitalization and a multidisciplinary evaluation [110, 111]. The authors conclude that intoxication by this class of compounds should be included in the differential diagnosis of new-onset psychosis.

More recently, simultaneous bilateral acute angle-closure crisis (AACC), a sight-threatening ocular emergency, triggered by cold and flu, as well as by preparations containing compounds with sympathomimetic properties [112, 113], or by a single oral dose of pseudoephedrine were documented [114]. The authors point out that the symptoms of simultaneous bilateral AACC may overlap with the flu-like symptoms for which the medications potentially triggering AACC are taken. Although the simultaneous bilateral onset of visual disturbance leads to a clinical suspicion of a central neurological pathology, the progressive nature of symptoms and their onset following the intake of a suspect drug should prompt Clinicians to consider drug-induced simultaneous bilateral AACC as a possible diagnosis [115]. In such cases, an urgent ophthalmological assessment is required.

Adverse drug reactions due to pseudoephedrine not only include numerous cases of pigmented $[116,117]$ and non-pigmented skin eruptions [118-120], but also some generalized scarlatiniform [121] or eczematous eruptions [122-124]. Moreover, cases of recurrent acute generalized exanthematous pustulosis and severe mucosal involvement have been described [125]. Mayo-Pampín E. et al., reported a case of acute generalized exanthematous pustulosis (AGEP), a severe and rare skin disease generally induced by certain antibiotics such as aminopenicillins and macrolides [126]. In all these cases, the causal role of pseudoephedrine has been confirmed by patch tests that provide the diagnosis of $\mathrm{T}$ lymphocyte-mediated hypersensitivity caused by this pharmacological compound [127]. Overall, the cases described suggest that, if such hypersensitivity is suspected, it is crucial for an appropriate diagnostic approach. 


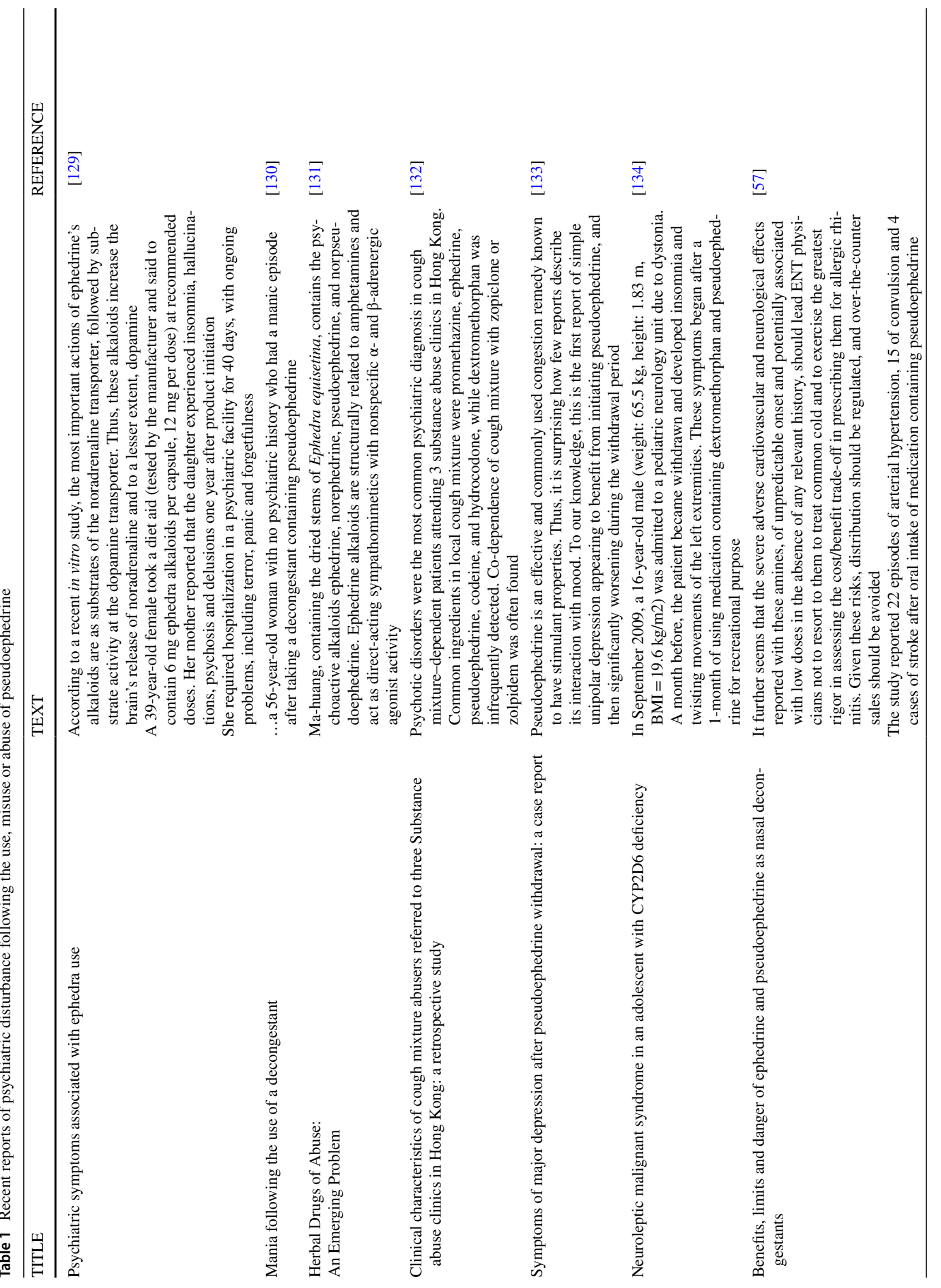




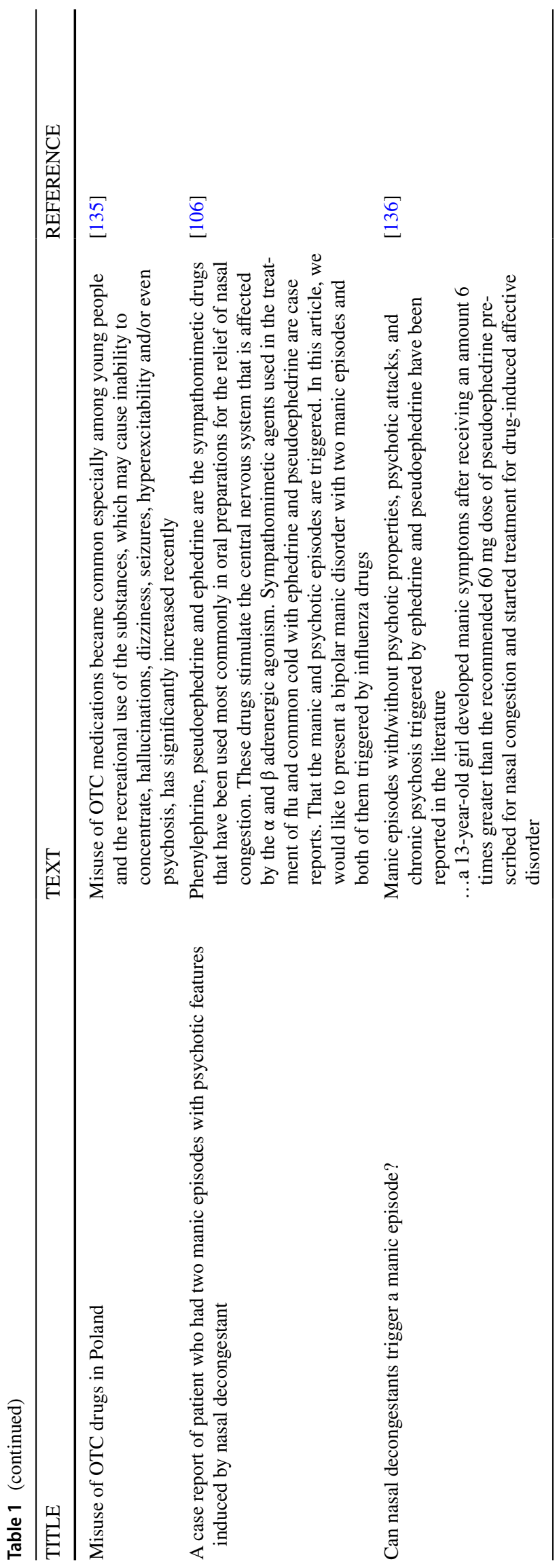

\section{Conclusions}

When compared to other pharmacological options for the treatment of obesity, the above evidence suggests that pseudoephedrine is absolutely contraindicated, in addition to pregnancy and breastfeeding, in all pre-existing cardiovascular and neuropsychiatric diseases. At any rate, risks arising from the use of pseudoephedrine depend significantly upon individual susceptibility, which, at the present state of knowledge, is not known, and, therefore, scarcely predictable, for all compounds of this class [75]. It should also be kept in mind that, even in clinical situations in which it is mandatory to achieve rapid weight loss (e.g., cases of severe obesity in which major surgery, including bariatric surgery, is indicated) the patient very often is already affected by cardiovascular comorbidities [128], representing, per se, a specific contraindication to the use of pseudoephedrine or congeners. Even in the absence of specific cardiovascular comorbidities, one should consider that in patients suffering from severe obesity, the use of pseudoephedrine can lead to unpredictable development of frank pathological conditions. A further aspect to consider is the neuro-psychological one, with special regard to the variable degree of individual susceptibility to pseudoephedrine. The unstable psychological structure of an obese individual, oppressed by the goal of loosing weight "at all costs", entails, given the intake of these substances with addictive properties, an increased risk of breaking the psychological balance, which can hesitate in behavioral disorders that are not always reversible [105].

Given the scanty clinical literature data, absolutely insufficient to draw reliable conclusions about its efficacy, the risk/benefit profile of pseudoephedrine in obesity is strongly leaning in favor of an increased and unpredictable cardiovascular and neuropsychiatric risk. In addition, a relevant impact on the toxic potential of pseudoephedrine in obesity is certainly represented by the number of OTC products, which, not needing a prescription, become the reason of uncontrolled occurrence of non reported, serious adverse reactions. Consequently, the treatment of obesity based on self-medications has became a quite challenging issue.

The frank and/or latent comorbidities, which characterize a chronic pathology such as obesity, expose these patients to a high risk of developing either severe arrhythmic events, and/or non-reversible neuropsychiatric disorders. The toxicological aspect linked to possible tachyphylaxis, which requires patients to move rapidly to higher doses to achieve the same effect over time, is also not negligible. In light of the above considerations, in light of the unfavorable risk/ benefit ratio presented by pseudoephedrine associated with its addictive potential, there appear no valid reasons for its systematic use in obesity of any order and degree. 
Acknowledgements The Authors are hugely grateful for the help and support of the Section V at the Consiglio Superiore di Sanità (National Italian High Health Council), Ministry of Health, which includes the following Members and Participants: Mario Barbagallo MD, Giuseppe Curigliano MD, Andrea Laghi MD, Maria Alario MD.

Authors' contributions RB, AG and GR conceived the scope and the structure of the manuscript and coordinated the research; AM, SF, RDM, NP wrote the manuscript; MC, CB, GC critically reviewed and edited the manuscript. RDM, SF, MC revised the reference list; AM, $\mathrm{CB}$, SF prepared figures and table.

\section{Declarations}

Conflicts of interest No conflict of interest.

Open Access This article is licensed under a Creative Commons Attribution 4.0 International License, which permits use, sharing, adaptation, distribution and reproduction in any medium or format, as long as you give appropriate credit to the original author(s) and the source, provide a link to the Creative Commons licence, and indicate if changes were made. The images or other third party material in this article are included in the article's Creative Commons licence, unless indicated otherwise in a credit line to the material. If material is not included in the article's Creative Commons licence and your intended use is not permitted by statutory regulation or exceeds the permitted use, you will need to obtain permission directly from the copyright holder. To view a copy of this licence, visit http://creativecommons.org/licenses/by/4.0/.

\section{References}

1. Hochberg Z. An Evolutionary Perspective on the Obesity Epidemic. Trends Endocrinol Metab. 2018;29:819-26.

2. Schwartz MW, Woods SC, Porte D, Seeley RJ, Baskin DG. Central nervous system control of food intake. Nature. 2000;404:661-71.

3. Schneider BE, Mun EC. Surgical Management of Morbid Obesity. Diabetes Care. 2005;28:475-80.

4. Bioimpedance analysis vs. DEXA as a screening tool for osteosarcopenia in lean, overweight and obese Caucasian postmenopausal females. HORMONES. 2017;16. http://www.hormones.gr/8689/ article/bioimpedance-analysis-vs-dexa-as-a\%E2\%80\% A6.html

5. Malnick SDH. The medical complications of obesity. QJM. 2006;99:565-79.

6. Wang YC, McPherson K, Marsh T, Gortmaker SL, Brown M. Health and economic burden of the projected obesity trends in the USA and the UK. The Lancet. 2011;378:815-25.

7. Calle EE, Rodriguez C, Walker-Thurmond K, Thun MJ. Overweight, Obesity, and Mortality from Cancer in a Prospectively Studied Cohort of U.S. Adults. N Engl J Med. 2003;348:1625-38.

8. Vainio H, International Agency for Research on Cancer, International Agency for Research on Cancer, editors. Weight control and physical activity. Lyon: IARC Press; 2002.

9. Castellana M, Conte E, Cignarelli A, Perrini S, Giustina A, Giovanella L, et al. Efficacy and safety of very low calorie ketogenic diet (VLCKD) in patients with overweight and obesity: A systematic review and meta-analysis. Rev Endocr Metab Disord. 2020;21:5-16.

10. Scheen AJ. The future of obesity: new drugs versus lifestyle interventions. Expert Opin Investig Drugs. 2008;17:263-7.

11. Haslam D. Weight management in obesity - past and present. Int J Clin Pract. 2016;70:206-17.
12. Garfield AS, Li C, Madara JC, Shah BP, Webber E, Steger JS, et al. A neural basis for melanocortin-4 receptor-regulated appetite. Nat Neurosci. 2015;18:863-71.

13. Xu Y, Elmquist JK, Fukuda M. Central nervous control of energy and glucose balance: focus on the central melanocortin system: Melanocortin networks regulate energy and glucose. Ann N Y Acad Sci. 2011;1243:1-14.

14. Collins S, Cao W, Daniel KW, Dixon TM, Medvedev AV, Onuma $\mathrm{H}$, et al. Adrenoceptors, Uncoupling Proteins, and Energy Expenditure. Exp Biol Med. 2001;226:982-90.

15. Antel J, Gregory PC, Nordheim U. CB ${ }_{1}$ Cannabinoid Receptor Antagonists for Treatment of Obesity and Prevention of Comorbid Metabolic Disorders. J Med Chem. 2006;49:4008-16.

16. Volkow ND, Wang G-J, Baler RD. Reward, dopamine and the control of food intake: implications for obesity. Trends Cogn Sci. 2011;15:37-46.

17. Grissom NM, Lyde R, Christ L, Sasson IE, Carlin J, Vitins AP, et al. Obesity at Conception Programs the Opioid System in the Offspring Brain. Neuropsychopharmacology. 2014;39:801-10.

18. Domecq JP, Prutsky G, Leppin A, Sonbol MB, Altayar O, Undavalli C, et al. Drugs Commonly Associated With Weight Change: A Systematic Review and Meta-analysis. J Clin Endocrinol Metab. 2015;100:363-70.

19. Desalermos A, Russell B, Leggett C, Parnell A, Ober K, Hagerich $\mathrm{K}$, et al. Effect of Obesogenic Medications on Weight-Loss Outcomes in a Behavioral Weight-Management Program: Obesogenic Drugs and a Weight-Loss Program. Obesity. 2019;27:716-23.

20. Clemmensen C, Finan B, Fischer K, Tom RZ, Legutko B, Sehrer $\mathrm{L}$, et al. Dual melanocortin-4 receptor and GLP - 1 receptor agonism amplifies metabolic benefits in diet-induced obese mice. EMBO Mol Med. 2015;7:288-98.

21. Troke RC, Tan TM, Bloom SR. The future role of gut hormones in the treatment of obesity. Ther Adv Chronic Dis. 2014;5:4-14.

22. Finan B, Yang B, Ottaway N, Smiley DL, Ma T, Clemmensen $\mathrm{C}$, et al. A rationally designed monomeric peptide triagonist corrects obesity and diabetes in rodents. Nat Med. 2015;21:27-36.

23. Koliaki C, Liatis S, le Roux CW, Kokkinos A. The role of bariatric surgery to treat diabetes: current challenges and perspectives. BMC Endocr Disord. 2017;17:50.

24. Cooper TC, Simmons EB, Webb K, Burns JL, Kushner RF. Trends in Weight Regain Following Roux-en-Y Gastric Bypass (RYGB) Bariatric Surgery. Obes Surg. 2015;25:1474-81.

25. Pories WJ. Bariatric Surgery: Risks and Rewards. J Clin Endocrinol Metab. 2008;93:s89-96.

26. Williams DM, Nawaz A, Evans M. Drug Therapy in Obesity: A Review of Current and Emerging Treatments. Diabetes Ther. 2020;11:1199-216.

27. Coulter AA, Rebello CJ, Greenway FL. Centrally Acting Agents for Obesity: Past, Present, and Future. Drugs. 2018;78:1113-32.

28. Vuori I. Health benefits of physical activity with special reference to interaction with diet. Public Health Nutr. 2001;4:517-28.

29. Jones BJ, Bloom SR. The New Era of Drug Therapy for Obesity: The Evidence and the Expectations. Drugs. 2015;75:935-45.

30. Rodgers RJ, Tschop MH, Wilding JPH. Anti-obesity drugs: past, present and future. Dis Model Mech. 2012;5:621-6.

31. Ruban A, Stoenchev K, Ashrafian H, Teare J. Current treatments for obesity. Clin Med Lond Engl. 2019;19:205-12.

32. Tak YJ, Lee SY. Long-Term Efficacy and Safety of AntiObesity Treatment: Where Do We Stand? Curr Obes Rep. 2021;10(1):14-30.

33. Mohammed SH, Habtewold TD, Birhanu MM, Sissay TA, Tegegne BS, Abuzerr S, et al. Neighbourhood socioeconomic status and overweight/obesity: a systematic review and metaanalysis of epidemiological studies. BMJ Open. 2019;9:e028238.

34. Wilding JPH, Jacob S. Cardiovascular outcome trials in obesity: A review. Obes Rev Off J Int Assoc Study Obes. 2021;22:e13112. 
35. Jackson VM, Breen DM, Fortin J-P, Liou A, Kuzmiski JB, Loomis AK, et al. Latest approaches for the treatment of obesity. Expert Opin Drug Discov. 2015;10:825-39.

36. O'Neil PM, Birkenfeld AL, McGowan B, Mosenzon O, Pedersen $\mathrm{SD}$, Wharton S, et al. Efficacy and safety of semaglutide compared with liraglutide and placebo for weight loss in patients with obesity: a randomised, double-blind, placebo and active controlled, dose-ranging, phase 2 trial. The Lancet. 2018;392:637-49.

37. Pi-Sunyer X, Astrup A, Fujioka K, Greenway F, Halpern A, Krempf M, et al. A Randomized, Controlled Trial of 3.0 mg of Liraglutide in Weight Management. N Engl J Med. 2015;373:11-22.

38. on behalf of the NN8022-1923 Investigators, Wadden TA, Hollander P, Klein S, Niswender K, Woo V, et al. Weight maintenance and additional weight loss with liraglutide after low-calorie-diet-induced weight loss: The SCALE Maintenance randomized study. Int J Obes. 2013;37:1443-51.

39. Cefalu WT, Leiter LA, Yoon K-H, Arias P, Niskanen L, Xie J, et al. Efficacy and safety of canagliflozin versus glimepiride in patients with type 2 diabetes inadequately controlled with metformin (CANTATA-SU): 52 week results from a randomised, doubleblind, phase 3 non-inferiority trial. The Lancet. 2013;382:941-50.

40. Nauck MA, Del Prato S, Meier JJ, Durán-García S, Rohwedder K, Elze M, et al. Dapagliflozin Versus Glipizide as Add-on Therapy in Patients With Type 2 Diabetes Who Have Inadequate Glycemic Control With Metformin: A randomized, 52-week, double-blind, activecontrolled noninferiority trial. Diabetes Care. 2011;34:2015-22.

41. Ridderstråle M, Andersen KR, Zeller C, Kim G, Woerle HJ, Broedl UC. Comparison of empagliflozin and glimepiride as add-on to metformin in patients with type 2 diabetes: a 104week randomised, active-controlled, double-blind, phase 3 trial. Lancet Diabetes Endocrinol. 2014;2:691-700.

42. Allison DB, Gadde KM, Garvey WT, Peterson CA, Schwiers ML, Najarian T, et al. Controlled-Release Phentermine/Topiramate in Severely Obese Adults: A Randomized Controlled Trial (EQUIP). Obesity. 2012;20:330-42.

43. Gadde KM, Allison DB, Ryan DH, Peterson CA, Troupin B, Schwiers ML, et al. Effects of low-dose, controlled-release, phentermine plus topiramate combination on weight and associated comorbidities in overweight and obese adults (CONQUER): a randomised, placebo-controlled, phase 3 trial. The Lancet. 2011;377:1341-52.

44. Fidler MC, Sanchez M, Raether B, Weissman NJ, Smith SR, Shanahan WR, et al. A One-Year Randomized Trial of Lorcaserin for Weight Loss in Obese and Overweight Adults: The BLOSSOM Trial. J Clin Endocrinol Metab. 2011;96:3067-77.

45. O’Neil PM, Smith SR, Weissman NJ, Fidler MC, Sanchez M, Zhang J, et al. Randomized Placebo-Controlled Clinical Trial of Lorcaserin for Weight Loss in Type 2 Diabetes Mellitus: The BLOOM-DM Study. Obesity. 2012;20:1426-36.

46. Smith SR, Weissman NJ, Anderson CM, Sanchez M, Chuang E, Stubbe S, et al. Multicenter, Placebo-Controlled Trial of Lorcaserin for Weight Management. N Engl J Med. 2010;363:245-56.

47. Apovian CM, Aronne L, Rubino D, Still C, Wyatt H, Burns C, et al. A randomized, phase 3 trial of naltrexone SR/bupropion SR on weight and obesity-related risk factors (COR-II). Obesity. 2013;21:935-43.

48. Greenway FL, Fujioka K, Plodkowski RA, Mudaliar S, Guttadauria $\mathrm{M}$, Erickson J, et al. Effect of naltrexone plus bupropion on weight loss in overweight and obese adults (COR-I): a multicentre, randomised, double-blind, placebo-controlled, phase 3 trial. The Lancet. 2010;376:595-605.

49. Krempf M, Louvet J-P, Allanic H, Miloradovich T, Joubert J-M, Attali $\mathrm{J}-\mathrm{R}$. Weight reduction and long-term maintenance after 18 months treatment with orlistat for obesity. Int J Obes. 2003;27:591-7.
50. Torgerson JS, Hauptman J, Boldrin MN, Sjostrom L. XENical in the Prevention of Diabetes in Obese Subjects (XENDOS) Study: A randomized study of orlistat as an adjunct to lifestyle changes for the prevention of type 2 diabetes in obese patients. Diabetes Care. 2004;27:155-61.

51. Danciu C, Muntean D, Alexa E, Farcas C, Oprean C, Zupko I, et al. Phytochemical Characterization and Evaluation of the Antimicrobial, Antiproliferative and Pro-Apoptotic Potential of Ephedra alata Decne. Hydroalcoholic Extract against the MCF-7 Breast Cancer Cell Line. Molecules. 2018;24:13.

52. Elhadef K, Smaoui S, Fourati M, Ben Hlima H, Chakchouk Mtibaa A, Sellem I, et al. A Review on Worldwide Ephedra History and Story: From Fossils to Natural Products Mass Spectroscopy Characterization and Biopharmacotherapy Potential. Evid Based Complement Alternat Med. 2020;2020:1-22.

53. Drew C, Knight G, Hughes D, Bush M. Comparison of the effects of D-(-)-ephedrine and L-(+)-pseudoephedrine on the cardiovascular and respiratory systems in man. Br J Clin Pharmacol. 1978;6:221-5.

54. Empey D, Young G, Letley E, John G, Smith P, McDonnell K, et al. Dose-response study of the nasal decongestant and cardiovascular effects of pseudoephedrine. Br J Clin Pharmacol. 1980;9:351-8

55. Persky AM, Berry NS, Pollack GM, Brouwer KLR. Modelling the cardiovascular effects of ephedrine. Br J Clin Pharmacol. 2004;57:552-62.

56. Vansal SS, Feller DR. Direct effects of ephedrine isomers on human $\beta$-adrenergic receptor subtypes. Biochem Pharmacol. 1999;58:807-10.

57. Laccourreye O, Werner A, Giroud J-P, Couloigner V, Bonfils P, Bondon-Guitton E. Benefits, limits and danger of ephedrine and pseudoephedrine as nasal decongestants. Eur Ann Otorhinolaryngol Head Neck Dis. 2015;132:31-4.

58. Katzung BG. Basic \& clinical pharmacology. New York: McGraw-Hill; 2018.

59. Kritzman J. Book Review Therapeutic Drugs Edited by Sir Colin Dollery. Approximately 2500 pp. in two volumes. New York, Churchill Livingstone, 1991. \$450. 0-443-02846-X. N Engl J Med. 1993;328:1651.

60. Hollander-Rodriguez JC, Montjoy HL, Smedra B, Prouty JP. Clinical Inquiry: Do oral decongestants have a clinically significant effect on BP in patients with hypertension? J Fam Pract. 2017;66:E1-2.

61. Ulus IH, Maher TJ, Wurtman RJ. Characterization of phentermine and related compounds as monoamine oxidase (mao) inhibitors. Biochem Pharmacol. 2000;59:1611-21.

62. Wellman PJ. Norepinephrine and the control of food intake. Nutrition. 2000;16:837-42.

63. de Sá PM, Richard AJ, Hang H, Stephens JM. Transcriptional Regulation of Adipogenesis. In: Terjung R, editor. Compr Physiol. Hoboken, NJ, USA: John Wiley \& Sons, Inc.; 2017. p. 63574. https://doi.org/10.1002/cphy.c160022.

64. Jang J, Jung Y, Chae S, Cho SH, Yoon M, Yang H, et al. Gangjihwan, a polyherbal composition, inhibits fat accumulation through the modulation of lipogenic transcription factors SREBP1C. PPAR $\gamma$ and C/EBP $\alpha$ J Ethnopharmacol. 2018;210:10-22.

65. Cypess AM, Weiner LS, Roberts-Toler C, Elía EF, Kessler SH, Kahn PA, et al. Activation of Human Brown Adipose Tissue by a $\beta 3$-Adrenergic Receptor Agonist. Cell Metab. 2015;21:33-8.

66. Hasani-Ranjbar S, Nayebi N, Larijani B, Abdollahi M. A systematic review of the efficacy and safety of herbal medicines used in the treatment of obesity. World J Gastroenterol. 2009;15:3073.

67. Kanfer I, Dowse R, Vuma V. Pharmacokinetics of oral decongestants. Pharmacotherapy. 1993;13:116S-128S. 
68. Li H, Zhang C, Wang J, Jiang Y, Fawcett JP, Gu J. Simultaneous quantitation of paracetamol, caffeine, pseudoephedrine, chlorpheniramine and cloperastine in human plasma by liquid chromatography-tandem mass spectrometry. J Pharm Biomed Anal. 2010;51:716-22.

69. Kuntzman RG, Tsa I, Brand L, Mark LC. The influence of urinary $\mathrm{pH}$ on the plasma half-life of pseudoephedrine in man and dog and a sensitive assay for its determination in human plasma. Clin Pharmacol Ther. 1971;12:62-7.

70. Wilkinson GR, Beckett AH. Absorption metabolism and excretion of the ephedrines in man. I. The influence of urinary $\mathrm{pH}$ and urine volume output. J Pharmacol Exp Ther. 1968;162:139-47.

71. Dickerson J, Perrier D, Mayersohn M, Bressler R. Dose tolerance and pharmacokinetic studies of $\mathrm{L}(+)$ pseudoephedrine capsules in man. Eur J Clin Pharmacol. 1978;14:253-9.

72. Brower V. Nutraceuticals: Poised for a healthy slice of the healthcare market? Nat Biotechnol. 1998;16:728-31.

73. Greenway F, Heber D, Raum W, Morales S. Double-Blind, Randomized, Placebo-Controlled Clinical Trials with NonPrescription Medications for the Treatment of Obesity. Obes Res. 1999;7:370-8.

74. Boullata JI, Nace AM. Safety Issues with Herbal Medicine. Pharmacotherapy. 2000;20:257-69.

75. Haller CA, Benowitz NL. Adverse Cardiovascular and Central Nervous System Events Associated with Dietary Supplements Containing Ephedra Alkaloids. N Engl J Med. 2000;343:1833-8.

76. Samenuk D, Link MS, Homoud MK, Contreras R, Theohardes TC, Wang PJ, et al. Adverse Cardiovascular Events Temporally Associated With Ma Huang, an Herbal Source of Ephedrine. Mayo Clin Proc. 2002;77:12-6.

77. Cantu C, Arauz A, Murillo-Bonilla LM, López M, Barinagarrementeria F. Stroke Associated With Sympathomimetics Contained in Overthe-Counter Cough and Cold Drugs. Stroke. 2003;34:1667-72.

78. Shekelle PG. Efficacy and Safety of Ephedra and Ephedrine for Weight Loss and Athletic Performance: A Meta-analysis. JAMA J Am Med Assoc. 2003;289:1537-45.

79. Food and Drug Administration, HHS. Final rule declaring dietary supplements containing ephedrine alkaloids adulterated because they present an unreasonable risk. Final rule. Fed Regist. 2004;69:6787-854.

80. Olivier P, Dugué A, Montastruc J-L. Effets indésirables cardiovasculaires et neurologiques centraux des sympathomimétiques utilisés comme décongestionnants de la sphère ORL : analyse de la Banque Nationale de Pharmacovigilance. Therapies. 2003;58:361-6.

81. Biyik I, Ergene O. Myocardial infarction associated with pseudoephedrine use and acute streptococcal infection in a boy with normal coronary arteries. Can J Cardiol. 2006;22:254-6.

82. Browning MG, Seddon JO, Yung LTM, Gough G. An unusual case of systemic cardiovascular side effects from the application of over-the-counter nasal decongestion drops. Case Rep. 2011;2011:bcr0620103078-bcr0620103078.

83. Manini AF, Kabrhel C, Thomsen TW. Acute myocardial infarction after over-the-counter use of pseudoephedrine. Ann Emerg Med. 2005;45:213-6.

84. Pederson KJ, Kuntz DH, Garbe GJ. Acute myocardial ischemia associated with ingestion of bupropion and pseudoephedrine in a 21-year-old man. Can J Cardiol. 2001;17:599-601.

85. Akay S, Ozdemir M. Acute coronary syndrome presenting after pseudoephedrine use and regression with beta-blocker therapy. Can J Cardiol. 2008;24:e86-8.

86. Fidan S, Izci S, Tellice M, Alizade E, Açar G. ST elevation myocardial infarction after use of pseudoephedrine: Which is more dangerous, the common cold itself or the medication used for it? Herz. 2015;40:144-6.

87. Sherid M, Samo S, Husein H, Sulaiman S, Vainder JA. Pseudoephedrine-induced ischemic colitis: Case report and literature review: Pseudoephedrine-induced ischemic colitis. J Dig Dis. 2014; 15:276-80.

88. Aziz M, Pervez A, Fatima R, Bansal A. Pseudoephedrine Induced Ischemic Colitis: A Case Report and Review of Literature. Case Rep Gastrointest Med. 2018;2018:1-4.

89. Klestov A, Kubler P, Meulet J. Recurrent ischaemic colitis associated with pseudoephedrine use. Intern Med J. 2001;31:195-6.

90. Lichtenstein GR, Yee NS. Ischemic Colitis Associated with Decongestant Use. Ann Intern Med. 2000;132:682.

91. Traino AA, Buckley NA, Bassett ML. Probable Ischemic Colitis Caused by Pseudoephedrine with Tramadol as a Possible Contributing Factor. Ann Pharmacother. 2004;38:2068-70.

92. Whitehouse AM, Duncan JM. Ephedrine Psychosis Rediscovered. Br J Psychiatry. 1987;150:258-61.

93. Kalix P. The pharmacology of psychoactive alkaloids from Ephedra and Catha. J Ethnopharmacol. 1991;32:201-8.

94. Angrist B, Rotrosen J, Kleinberg D, Merriam V, Gershon S. Dopaminergic agonist properties of ephedrine-theoretical implications. Psychopharmacology. 1977;55:115-20.

95. Volkow ND, Fowler JS, Wang GJ, Hitzemann R, Lieberman J, Angrist B. Dopaminergic modulation of frontal activity: Involvement in cocaine addiction. Biol Psychiatry. 1996;39:508-9.

96. Hagel JM, Krizevski R, Marsolais F, Lewinsohn E, Facchini PJ. Biosynthesis of amphetamine analogs in plants. Trends Plant Sci. 2012;17:404-12.

97. Wilson H, Woods D. Pseudoephedrine causing mania-like symptoms. N Z Med J. 2002;115:86.

98. Doyle H, Kargin M. Herbal stimulant containing ephedrine has also caused psychosis. BMJ. 1996;313:756-756.

99. Capwell RR. Ephedrine-induced mania from an herbal diet supplement. Am J Psychiatry. 1995;152:647a-647.

100. Roxanas MG, Spalding J. EPHEDRINE ABUSE PSYCHOSIS. Med J Aust. 1977;2:639-40.

101. Jacobs KM, Hirsch KA. Psychiatric Complications of MaHuang. Psychosomatics. 2000;41:58-62.

102. Lake CR, Tenglin R, Chernow B, Holloway HC. Psychomotor Stimulant-Induced Mania in a Genetically Predisposed Patient: A Review of the Literature and Report of a Case. J Clin Psychopharmacol. 1983;3:97-9.

103. Chait LD. Factors influencing the reinforcing and subjective effects of ephedrine in humans. Psychopharmacology. 1994;113:381-7.

104. Emmanuel NP, Jones C, Lydiard RB. Use of Herbal Products and Symptoms of Bipolar Disorder. Am J Psychiatry. 1998;155:1626b-1626.

105. Kutulus-Calli. Pseudo-ephedrine induced mania in a schizoaffective disorder patient having remission for ten years. Klin Psikofarmakol Bul. 2014. p. S293.

106. Kandeger A, Tekdemir R, Sen B, Selvi Y. A case report of patient who had two manic episodes with psychotic features induced by nasal decongestant. Eur Psychiatry. 2017;41:S428.

107. Conway CR, Ziaee L, Langenfeld SJ. Ephedrine-induced emergence of bipolar symptoms. Bipolar Disord. 2006;8:204-5.

108. Miller MG. Visual hallucinations in children receiving decongestants. BMJ. 1984;288:1688.

109. Sankey RJ, Nunn AJ, Sills JA. Visual hallucinations in children receiving decongestants. BMJ. 1984;288:1369.

110. Sauder KL, Brady WJ, Hennes H. Visual hallucinations in a toddler: Accidental ingestion of a sympathomimetic over-thecounter nasal decongestant. Am J Emerg Med. 1997;15:521-6.

111. Soutullo CA, Cottingham EM, Keck PE. Psychosis associated with pseudoephedrine and dextromethorphan. J Am Acad Child Adolesc Psychiatry. 1999;38:1471-2.

112. Ah-Kee EY, Li Yim JF. Bilateral acute angle closure glaucoma precipitated by over the counter oral decongestant. Int J Ophthalmol. 2014;7:387-8. 
113. Rudkin AK, Gray TL, Awadalla M, Craig JE. Bilateral simultaneous acute angle closure glaucoma precipitated by non-prescription cold and flu medication: Drug-induced angle closure glaucoma. Emerg Med Australas. 2010;22:477-9.

114. Spencer BG, Baskin J, Giarola BF, Craig JE. Single Dose of Pseudoephedrine Induces Simultaneous Bilateral Acute Angle Closure Crisis. Case Rep Ophthalmol. 2019;10:365-8.

115. Ah-kee EY, Egong E, Shafi A, Lim LT, Yim JL. A review of drug-induced acute angle closure glaucoma for non-ophthalmologists. Qatar Med J. 2015;2015:6.

116. Hauken M. Fixed Drug Eruption and Pseudoephedrine. Ann Intern Med. 1994;120:442.

117. Özkaya E, Elinç-Aslan MS. Pseudoephedrine May Cause "Pigmenting" Fixed Drug Eruption. Dermatitis. 2011;22:E7-9.

118. Matsumoto K, Mikoshiba H, Saida T. Nonpigmenting solitary fixed drug eruption caused by a Chinese traditional herbal medicine, ma huang (Ephedra Hebra), mainly containing pseudoephedrine and ephedrine. J Am Acad Dermatol. 2003;48:628-30.

119. Quan MB, Chow WC. NONPIGMENTING FIXED DRUG ERUPTION AFTER PSEUDOEPHEDRINE. Int J Dermatol. 1996;35:367-70.

120. Vidal C, Pérez-Carral C, Armisén M, Prieto A. Nonpigmenting Fixed Drug Eruption due to Pseudoephedrine. Ann Allergy Asthma Immunol. 1998;80:309-10.

121. Tognetti L, Lotti T, Giorgini S. Erythema multiforme-like eruption from a slimming drug preparation cutaneous adverse drug reaction. Indian Dermatol Online J. 2011;2:78.

122. Auljicana M, Urrutia I, Echkhipla S, Munoz D, de Corkes LF. Sensitization to ephedrine in oral anticatarrhal drugs. Contact Dermatitis. 1991;24:223-4.

123. Villas Martínez F, Joral Badas A, Garmendia Goitia JF, Aguirre I. Generalized dermatitis due to oral ephedrine. Contact Dermatitis. 1993;29:215-6.

124. Sánchez TS, Sánchez-Pérez J, Aragüés M, García-Díaz A. Flareup reaction of pseudoephedrine baboon syndrome after positive patch test. Contact Dermatitis. 2000;42:312-3.

125. Assier-Bonnet H, Viguier M, Dubertret L, Revuz J, Roujeau JC. Severe adverse drug reactions due to pseudoephedrine from over-the-counter medications: ADR to Pseudoephedrine. Contact Dermatitis. 2002;47:165-82.
126. Mayo-Pampín E, Flórez ?, Feal C, Conde A, Abalde M, De La Torre C, et al. Acute Generalized Exanthematous Pustulosis due to Pseudoephedrine with Positive Patch Test. Acta Derm Venereol. 2006;86:542-3.

127. Tanno LK, Darlenski R, Sánchez-Garcia S, Bonini M, Vereda A, Kolkhir P, et al. International survey on skin patch test procedures, attitudes and interpretation. World Allergy Organ J. 2016;9:8.

128. Gerber P, Anderin C, Thorell A. Weight loss prior to bariatric surgery: An updated review of the literature. Scand J Surg. 2015;104:33-9.

129. Maglione M, Miotto K, Iguchi M, Hilton L, Shekelle P. Psychiatric symptoms associated with ephedra use. Expert Opin Drug Saf. 2005;4:879-84.

130. Stuer K, Claes S. [Mania following the use of a decongestant]. Tijdschr Voor Psychiatr. 2007;49:125-9.

131. Richardson WH, Slone CM, Michels JE. Herbal drugs of abuse: an emerging problem. Emerg Med Clin North Am. 2007;25:435-57.

132. Tang AK, Tang WK, Liang HJ, Chan F, Mak SC, Ungvari GS. Clinical characteristics of cough mixture abusers referred to three substance abuse clinics in Hong Kong: a retrospective study. East Asian Arch Psychiatry. 2012 Dec;22(4):154-9.

133. Webb J, Dubose J. Symptoms of Major Depression After Pseudoephedrine Withdrawal: A Case Report. J Neuropsychiatry Clin Neurosci. 2013;25:E54-5.

134. Butwicka A, Krystyna S, Retka W, Wolańczyk T. Neuroleptic malignant syndrome in an adolescent with CYP2D6 deficiency. Eur J Pediatr. 2014;173:1639-42.

135. Zaprutko T, Koligat D, Michalak M, Wieczorek M, Józiak M, Ratajczak M, et al. Misuse of OTC drugs in Poland. Health Policy. 2016;120:875-81.

136. Kandeger A, Tekdemir R, Sen B, Selvi Y. Can nasal decongestants trigger a manic episode? Dusunen Adam J Psychiatry Neurol Sci. 2020;33:96-98

Publisher's Note Springer Nature remains neutral with regard to jurisdictional claims in published maps and institutional affiliations. 